\title{
La experiencia social histórica de asistencia al cine en Monterrey (Nuevo León, México) durante las décadas de 1930 a 1960
}

\section{José Carlos Lozano ${ }^{1}$ Philippe Meers ${ }^{2}$ Daniel Biltereyst ${ }^{3}$}

Recibido: 2015-09-08

Enviado a pares: 2015-09-08
Aprobado por pares: 2015-10-27

Aceptado: 2015-11-11

DOI: 10.5294/pacla.2016.19.3.2

Para citar este artículo / to reference this article / para citar este artigo Lozano, J.C., Meers, P. y Biltereyst D. (2016). La experiencia social histórica de asistencia al cine en Monterrey (Nuevo León, México) durante las décadas de 1930 a 1960. Palabra Clave, 19(3), 691-720. DOI: 10.5294/pacla.2016.19.3.2

\section{Resumen}

En este trabajo se analiza la experiencia social histórica de asistencia al cine en Monterrey (Nuevo León, México) durante las décadas de 1930 a 1960, según entrevistas focalizadas con 28 informantes mayores de 65 años. En los resultados, se destaca la importancia histórica de las salas de cine, así como las películas y los actores estadounidense y mexicanos, en la vida personal, familiar y colectiva de Monterrey, dentro del contexto histórico de su transformación en una de las ciudades más grandes e industrializadas del país.

\section{Palabras clave}

Historia social del cine; audiencias cinematográficas; nueva historia del cine; asistencia al cine; cine en México (Fuente: Tesauro de la Unesco).

\footnotetext{
Tecnológico de Monterrey, México. jclozano16@gmail.com

Universidad de Amberes, Bélgica. philippe.meers@uantwerpen.be

Universidad de Gante, Bélgica. daniel.biltereyst@ugent.be
} 


\section{The Historical Social Experience of Cinema Attendance in Monterrey (Nuevo Leon, Mexico) during the Period from 1930 to 1960}

\section{Abstract}

The historical social experience of cinema attendance in Monterrey (Nuevo Leon, Mexico) during the period from 1930 to 1960 is analyzed in this article, based on interviews with 28 informants who were over 65 years old. The results highlight the historical importance of movie theaters, American and Mexican films and screen stars in the personal, family and collective life of Monterrey, within the historical context of its transformation into one of the largest and most industrialized cities in the country.

\section{Keywords}

Social history of cinema; movie audiences; new history of cinema; cinema attendance; cinema in Mexico (Source: Unesco Thesaurus). 


\section{A experiência social histórica de audiência cinematográfica em Monterrey (Nuevo León, México) durante as décadas de 1930 a 1960}

\section{Resumo}

Neste trabalho, analisa-se a experiência social histórica de audiência cinematográfica em Monterrey (Nuevo León, México) durante as décadas de 1930 a 1960, segundo entrevistas focalizadas com 28 informantes com mais de 65 anos. Nos resultados, destaca-se a importância histórica das salas de cinema, bem como dos filmes e dos atores estadunidenses e mexicanos na vida pessoal, familiar e coletiva de Monterrey, dentro do contexto histórico de sua transformação numa das maiores e mais industrializadas cidades do país.

\section{Palavras-chave}

História do cinema; audiências cinematográficas; nova história do cinema; comparecimento ao cinema; cinema no México (Fonte: Tesauro da Unesco). 
Mediante el análisis histórico de la recepción y varios tipos de investigación etnográfica, un creciente número de académicos en distintas partes del mundo han ido más allá del tradicional análisis de las películas como textos, típico de los estudios de cine, realizando estudios empíricos de la exhibición, la programación y el consumo social y cultural simbólico del cine y concentrándose particularmente en la reconstrucción de las experiencias cotidianas del cine a través del testimonio de los públicos (Allen, 1990; Kuhn, 2002; Stokes y Maltby, 1999; Meers, Biltereyst y Van de Vijver, 2010; Richards, 2003; Taylor, 1989). A este enfoque novedoso para estudiar el cine que toma en cuenta el contexto de su recepción en espectadores concretos en periodos específicos y en regiones culturales y geográficas particulares se le ha designado con el nombre de Nueva Historia del Cine (Maltby, Biltereyst y Meers, 2011).

Como una contribución a esta nueva perspectiva sobre la historia del cine, el presente artículo reporta y discute los hallazgos de un estudio realizado en Monterrey (México), la tercera ciudad más poblada de México, ubicada en el noreste del país, a 230 kilómetros de la frontera con Texas. Basado en la misma metodología del proyecto belga La ciudad iluminada (Biltereyst, Meers y Van de Vijver, 2011) para facilitar la comparación con proyectos europeos similares, nuestro trabajo se centró en el análisis de la experiencia social histórica de la asistencia al cine de veintiocho personas entre 65 y 95 años, indagando sobre sus memorias y percepciones sobre los cines, las películas y las actividades alrededor de ellas cuando eran niños, jóvenes y adultos jóvenes. Mediante temas claves relativos a la experiencia social del cine, exploramos los diferentes significados e interpretaciones del cine en este grupo de edad y las condiciones que estructuraron sus experiencias de asistencia a las salas de cine.

\section{Monterrey como caso de estudio}

Después de fundarse por los conquistadores españoles en 1595, Monterrey fue por siglos una pequeña villa aislada en los territorios del norte, hasta que la guerra entre México y los Estados Unidos en 1846-1848 culminó con el establecimiento del Río Grande (llamado Bravo del lado mexicano) como la nueva frontera entre ambos países. Este cambio en la ubicación 
de la frontera convirtió a Monterrey en una ciudad en relativa proximidad con el poderoso vecino del norte, abriendo oportunidades para el comercio con los Estados Unidos y revistiendo a Monterrey de un poder político y económico importante al constituirse en el eje del nuevo sistema de aranceles y revisiones aduaneras para las importaciones y las exportaciones establecidas por el Gobierno federal (Cerutti, Ortega y Palacios, 2000; Kumar, 2011; Vellinga, 1988).

En la década de 1890, después de la llegada del ferrocarril a la ciudad, que permitió su conexión tanto a la Ciudad de México como a otras partes del país y Texas, Monterrey cambió de ser un simple centro de distribución a ser una población plenamente industrializada. Así, de 7000 habitantes que tenía en 1803, Monterrey pasó a fines de la década de 1890 a contar con 60 000, debido a la rápida industrialización de la ciudad (Kumar, 2011). En 1903 Monterrey se convirtió virtualmente en la Pittsburgh latinoamericana con la apertura de Fundidora Monterrey, la cual creó miles de empleos durante diversas décadas.

Fue al final de la década de 1890 que el cine arribó a Monterrey. En mayo de 1897, la Exposición Imperial, en su recorrido por las principales ciudades del país, pasó por la ciudad con su repertorio de 250 vistas (De los Reyes, 1983, pp. 158-159). Según el testimonio de un cronista local, en octubre de 1898, asimismo, una compañía de cinematógrafo visitó Monterrey, y por varias semanas exhibió “vistas móviles” (Saldaña, 1988). En el mismo año, un empresario local presentó en la ciudad una cámara Lumière y estableció una de las primeras exhibiciones de cine en el centro de la ciudad (Vizcaya, 1971, p. 124). De 1898 a 1915, las películas fueron exhibidas en todo tipo de lugares, desde parques y calles hasta tiendas de zarzuela y vodevil (Saldaña, 1988).

Durante las primeras décadas del siglo XX, Monterrey continuó creciendo vertiginosamente y se consolidó como la capital industrial de México. Los industriales regiomontanos se diversificaron y crearon muchas otras fábricas y empresas. La población, para 1920, había alcanzado 88000 habitantes. Pese a la perturbación ocasionada por la Revolución mexicana 
(1910-1916) y la significativa caída de la demanda por bienes y servicios a consecuencia de ella, Monterrey no fue afectado tan seriamente como otras partes del país debido a su condición urbana e industrial y a que no constituía una plaza políticamente significativa en el ámbito nacional (Cerutti, Ortega y Palacios, 2000, p. 9). Para mediados de la década de 1920, la economía de la población se había recuperado por completo y empezaba a crecer de nuevo. Monterrey se expandía con una ciudadanía compuesta por una élite comercial, una creciente clase media de gerentes y empleados de nivel ejecutivo, así como de miles de obreros.

Para 1930 ya había 130000 personas viviendo en la ciudad y para 1940 había alcanzado los 186000 . Miles de habitantes de otras partes del noreste y del resto de la república migraron a Monterrey para buscar trabajo durante ese periodo. De acuerdo con Kumar (2011), para 1940, 26 \% de la población estaba constituida por migrantes, y para 1950 ese porcentaje había crecido a $30 \%$. En una ciudad con una infraestructura cultural, artística e intelectual mucho menor que la de Ciudad de México, Guadalajara y otras urbes del país, la asistencia al cine era una de las opciones de entretenimiento más baratas y accesibles. Ir al cine, para la población de Monterrey, incluso nuestra muestra de informantes, se convirtió en el medio de diversión más popular.

\section{Método}

El uso de la historia oral para investigar la experiencia social de la asistencia al cine desde una perspectiva histórica tiene sus complejidades metodológicas. Ciertamente, la historia oral da voz a aquellas memorias que rara vez se registran y que normalmente se perderían. Para identificar las experiencias vitales de públicos comunes y corrientes dentro de su propio contexto social, histórico y cultural y entender el papel del cine en la vida cotidiana y dentro de la cultura del entretenimiento y el tiempo libre, parece recomendable optar por metodologías cualitativas, diseños de investigación pequeños y enfoques etnográficos en lo micro: entrevistas, observaciones, diarios $\mathrm{y}$ todo tipo de registros escritos, testimonios y memorias.

Una dificultad central de lo que Annette Kuhn ha llamado "etnohistoria” (2002, p. 6) no reside tanto en la recopilación de historias, anécdo- 
tas y memorias, como en su análisis e interpretación. Los investigadores están obligados a tomar en cuenta que las memorias son altamente selectivas y subjetivas y que experimentan cierto grado de distorsión a lo largo del tiempo, lo cual presenta problemas para su cabal interpretación. La memoria, por supuesto, no es un repositorio pasivo de hechos, sino un proceso activo de producción de significados. Los procesos selectivos de memorias personales y colectivas incluyen estrategias de repetición, fragmentación, narrativa (el deseo de contar una "buena historia"), el uso de anécdotas y las tácticas de olvido, creación y sobreénfasis de eventos específicos. Estas últimas se refieren a memorias que se han priorizado y que se han conservado como más relevantes para el informante, dada su particular importancia, mientras que muchas otras memorias se relegan y minimizan. En este sentido, Stacey utiliza el término memorias valoradas para describir aquellos recuerdos de eventos en los que los respondientes estaban personalmente involucrados (1998, p. 56). Al entrevistar a informantes mayores de 65 años y preguntarles sobre su experiencia de asistencia al cine cuando niños o jóvenes, es importante tomar en cuenta que los grados de fragmentación, distorsión y énfasis pudiesen ser aún más selectivos y subjetivos dado el mayor paso de tiempo.

El propósito de la historia oral sobre asistencia al cine no es reconstruir objetivamente el pasado a partir de las memorias subjetivas de los informantes, sino observar críticamente la recreación de sus memorias sobre su asistencia al cine. En este sentido, Kuhn (2002, pp. 9-12) utiliza el término texto de memoria, es decir, el cómo la gente recuerda es tanto un texto por ser descifrado como las memorias mismas de las que se habla. Estas consideraciones tienen importantes implicaciones en la investigación. Una de ellas es que las memorias sobre la asistencia al cine con frecuencia se encuentran empañadas por la nostalgia, dada la desaparición de la cultura cinematográfica en la que crecieron los informantes. Como señala Kuhn (2004), las memorias sobre la asistencia al cine se caracterizan por una temática recurrente pasado/presente, lo cual implica que no pueden entenderse sin tomar en cuenta su invariable relación con el presente. El tiempo recordado, agrega, no debe confundirse con el tiempo histórico. A las memorias sobre el pasado, de acuerdo con Kuhn, se les puede llamar "tiempo 
vivido" (2004, p. 106), experimentado tanto colectiva como individualmente, un tanto incongruente con la temporalidad lineal del tiempo histórico. Al discutir e interpretar las memorias sobre la asistencia al cine de nuestros informantes de Monterrey sobre las décadas de 1930 a 1960, hemos tratado de no olvidar lo anterior.

Los veintiocho respondientes regiomontanos fueron seleccionados y contactados en asilos de ancianos o a través del círculo social de conocidos de los entrevistadores. Como es usual en la investigación cualitativa, la representación estadística no fue nunca el objetivo de esta parte del estudio. Por el contrario, lo que se buscó fue obtener la mayor variación posible respecto del nivel socioeconómico, género y puntos de vista ideológicos para explorar la mayor cantidad posible de rutinas, ideas y motivos relacionados con la asistencia al cine. La frecuencia de consumo cinematográfico también variaba significativamente entre los informantes, desde los asiduos cinéfilos hasta los que solo ocasionalmente asistían a alguna sala. La mayoría de los entrevistados eran nativos de Monterrey y sus memorias de asistencia al cine se referían, por tanto, de manera exclusiva a los establecimientos locales. Otros, sin embargo, habían nacido o crecido en otras ciudades de la región, por lo que parte de sus recuerdos se referían a otras salas y otras poblaciones.

Las entrevistas se realizaron durante 2010 y 2011 en el contexto de las casas o los asilos de los propios informantes. Las entrevistas fueron semiestructuradas, de acuerdo con un cuestionario temático que permitió mantener enfocadas las conversaciones, pero dejando al mismo tiempo espacio para permitir y propiciar las memorias espontáneas y las propias historias de los respondientes, lo cual fue crucial, pues muchos de los informantes se encontraban altamente motivados y deseaban hablar sobre sus memorias vívidas, con frecuencia refiriéndose a momentos específicos que recordaban. La entrevista se planteó en tres etapas distintas, en busca de cubrir primero las memorias de la infancia, luego de la juventud y, finalmente, de la adultez, repitiendo en algunas ocasiones las mismas preguntas. Los entrevistadores explicaban a los informantes, al inicio, el deseo de recuperar sus memorias para cada etapa, recordándoles mediante cada pregunta que se 
centraran en el periodo adecuado. Lo anterior, siguiendo a Jancovich (2011), para indagar cómo las memorias de asistencia al cine difieren y se matizan a través de la etapa temporal en que se vivieron, a su calendarización dentro de las vidas de los informantes, así como el contexto social de la ciudad:

Durante el transcurso de su vida, el individuo atravesará por diferentes etapas e identidades que más que biológicamente son determinadas por lo social y lo cultural. Durante estas etapas, se encuentran asimismo en diferentes tipos de relaciones, y éstas pueden tener un impacto significativo en su consumo de cine (pp. 89-90).

Por supuesto, a pesar de nuestra estrategia de reiterar en las preguntas la etapa sobre la que sugeríamos se concentraran, los informantes alternaron en sus respuestas memorias de los diferentes momentos de su vida, pero se logró obtener suficiente información sistemática sobre ellos. La duración de las entrevistas varió dependiendo de la capacidad narrativa de cada informante, pero promediaron alrededor de una hora.

\section{Tabla 1. Edad y género de los informantes}

\begin{tabular}{|c|c|c|c|}
\hline Edad & Femenino & Masculino & Total \\
\hline $65-69$ & 4 & 2 & 6 \\
\hline $70-74$ & 4 & & 4 \\
\hline $75-79$ & 2 & 1 & 3 \\
\hline $80-84$ & 3 & 4 & 7 \\
\hline $85-89$ & 3 & 4 & 7 \\
\hline $95-99$ & & 1 & 1 \\
\hline Total & 16 & 12 & 28 \\
\hline
\end{tabular}

Fuente: elaboración propia.

La mitad de los informantes (entrevistados durante 2010 o 2011) eran niños o jóvenes durante la década de 1930; la otra mitad durante las década de 1940 y 1950.

Las entrevistas fueron transcritas de manera literal y analizadas utilizando el programa HyperRESEARCH. Para el análisis, organizamos las memorias de los informantes de acuerdo con una selección de categorías, como la selección de sala cinematográfica, frecuencia de asistencia al cine, personas con las que acostumbraba ir, información sobre películas 
específicas y motivos para ir al cine. Dada la homogeneidad relativa de este grupo de edad y semejanzas consistentes entre sus memorias y discurso sobre asistencia al cine, la muestra parece haber sido suficiente para identificar las principales experiencias vividas de la asistencia al cine en este grupo de informantes de Monterrey.

Tomando en cuenta que el apogeo de asistencia al cine de acuerdo con el ciclo de vida de los informantes se daba alrededor de los 25 años, la mayoría de las anécdotas e historias se centraron entre 1935 y 1965. A pesar de ser un periodo relativamente amplio, el cual coincide tanto con la época de mayor auge de la asistencia al cine como de su declive, los entrevistados hablaban de él como si fuera un periodo homogéneo.

\section{Resultados}

\section{Salas de cine y exhibición de películas de las décadas de 1930 a 1960}

Antes de discutir las memorias de los informantes sobre su asistencia al cine (en la mitad de ellos a partir de los inicios de la década de 1930), parece conveniente discutir la disponibilidad de salas de cine en Monterrey y el tipo y número de películas que exhibían entre las décadas de 1930 y 1960, para establecer el contexto histórico de la oferta cinematográfica prevaleciente.

Con una población de 134000 habitantes, Monterrey contaba en 1932 con solo ocho cines en la ciudad. Para 1942, ese número se había incrementado a 25, ampliando las opciones desde el centro histórico hacia otras partes de la ciudad, en particular la avenida Madero, muy popular entre las clases medias regiomontanas durante esos años, pero que a partir de la década de 1960 se convertiría en área de clase trabajadora, debido al establecimiento de fábricas y viviendas para los obreros. Diez años después, en 1952, el número de cines había disminuido a 20, y para 1962, con el fin de la época de oro del cine mexicano y la popularización de otros medios de entretenimiento para las clases medias (Rosas, 2000; Lozano et al., 2012), a solo 14. Además de los grandes palacios y los cines regulares ubicados en el centro de la ciudad, existían alrededor de 46 cines de barrio llamados 
popularmente "terrazas". Estos cines eran establecimientos modestos, con bancas de madera en lugar de asientos individuales, y sin techo, y se localizaban mayormente en barrios de clase trabajadora, que proyectaban películas de segunda o tercera corridas al oscurecer a precios muy bajos. Las “terrazas” empezaron a proliferar en la década de 1940 en Monterrey, pero su crecimiento máximo se dio durante la siguiente década.

Durante las décadas de 1920 y 1930, las películas de Hollywood dominaron casi por completo la exhibición cinematográfica en Monterrey (Lozano et al., 2012). Hacia finales de la década de 1930, sin embargo, el apoyo de Hollywood debido al inicio de la Segunda Guerra Mundial, así como a políticas gubernamentales propias favorables a la producción y distribución de películas mexicanas, propiciaron el surgimiento de la llamada Época de Oro del Cine Mexicano (Fein, 1996; Peredo, 2009; Silva, 2011). Las pantallas de Monterrey, al igual que en el resto del país, empezaron a programar amplia y consistentemente filmes nacionales, y por primera vez los espectadores tuvieron la posibilidad de escoger entre cintas estadounidenses y mexicanas. Para la mitad de la década 1950, la asistencia a las salas de cine había iniciado su declive, proceso que se acentuaría durante la década de 1960 debido a las razones mencionadas arriba.

\section{Selección de cines, no filmes}

Los autores que trabajan desde la Nueva Historia del Cine han encontrado sistemáticamente que los informantes acudían a salas de cine específicas no porque ahí se exhibiese el filme que deseaban ver, sino por la familiaridad y seguridad que ofrecían al pertencer a su barrio y a su mapa mental de la ciudad. De acuerdo con Maltby (2011, p. 9), las historias de vida con asistentes al cine hablan de manera consistente sobre los ritmos locales en la circulación de películas y sobre la manera en que la experiencia de asistir al cine se vinculaba a lugares específicos y se moldeaba por las comunidades de vida en familia, los lugares de trabajo, el barrio y la comunidad. Kuhn (2002, p. 33), por su parte, reporta que sus entrevistadas (niñas o jóvenes en la década de 1930) incluso estructuraban sus memorias según la reconstrucción de su andar por las calles de su infancia o adolescencia, desde sus hogares hasta el cine más próximo. Meers, Biltereyst y Van de Vijver 
(2010, p. 275), asimismo, concluyeron que las memorias de sus respondientes se enfocaban contundentemente en el acto social de ir al cine y no en películas específicas.

Nuestros hallazgos en Monterrey, pese a la enorme distancia geográfica con Inglaterra y Bélgica, así como a las múltiples diferencias culturales, muestran una gran similitud con dichos resultados previos. La mayoría de los informantes regiomontanos comentó que en su infancia o juventud asistían siempre al mismo cine sin importar la película que estuviesen exhibiendo, pues lo que importaba para ellos era su cercanía al hogar y su integración al espacio geográfico que para ellos era familiar. Dentro de dicho espacio, tendían a preferir las grandes salas sobre las pequeñas, y evitaban los cines de bajo estatus por no corresponder a su nivel social. Algunos, los que provenían de nivel socioeconómico bajo, acostumbraban a asistir a la "terraza" (cine de barrio) más cercana a sus domicilios a ver películas de segunda o tercera corridas.

De cualquier forma, era claro en las entrevistas que las salas de cine estaban claramente conectadas con los "mapas mentales" de los informantes sobre su ciudad. De hecho, muchos de ellos mencionaban las direcciones de las casas en que vivían en esa época y a continuación se referían a la ubicación del cine al que asistían regularmente, señalando asimismo otros sitios relevantes, como los mercados, los edificios o las calles cercanas, en reflejo de la relación emocional que le adjudicaban en sus esquemas topográficos a su sala cinematográfica favorita. Para los informantes de nivel socioeconómico bajo, en su infancia y juventud, los grandes cines eran inaccesibles, por lo que acostumbraban a asistir a la terraza más cercana. Algunos de estos entrevistados, en tono orgulloso, comentaban que ya como jóvenes adultos, al contar con trabajo y por tanto con un sueldo, se daban el lujo de asistir de vez en cuando a alguno de los grandes cines del centro, sobre todo cuando había alguna película mexicana de estreno que representaba un gran acontecimiento.

Nelly, de 70 años, respondía así a la pregunta sobre su cine preferido cuando niña: 
Nelly (nacida en 1941): Bueno, no era que lo prefiriera; se trataba más bien de qué sala de cine se encontraba más cerca de tu casa... [por lo tanto] nuestros padres siempre escogían el Cine Rodríguez para nosotros.

Algunos de los entrevistados también seleccionaban los cines de acuerdo con sus características físicas. Algunos mencionaban los grandes palacios como sus favoritos, por su decoración y su arquitectura.

ElenA (1929): A mí me gustaba ir a dos cines en particular: El Elizondo, al que derrumbaron después y el Florida... Esos eran mis cines favoritos cuando era niña.

¿Por qué le gustaban esos cines?

Elena: Su decoración era bellísima... Uno de ellos, el Elizondo, tenía una decoración oriental, con pagodas y estatuas. Y en el Florida, si volteabas al techo cuando apagaban las luces, podías ver como estrellas centellando.

Blanca (1942): Yo recuerdo las cortinas. En el Cine Palacio, uno de los más, como te diré, de más clase, las cortinas se abrían y tu decías: "¿Cómo es posible que tengan unas cortinas tan largas, hermosas y elegantes?". Recuerdo claramente los asientos, muy cómodos y bien afianzados al suelo, y las alfombras y los pasillos.

Algunos informantes, sin embargo, aceptaban haber evitado ciertos cines, a pesar de su cercanía, debido a que eran para personas de nivel socioeconómico más bajo que el suyo. En una ciudad con una gran presencia de trabajadores y migrantes debido a las numerosas fábricas y la bonanza industrial, así como a una creciente clase media de empleados de cuello blanco y gerentes, las diferencias de estatus se reflejaban en la selección de las salas de cine. Olga (1923), a pesar de intentar usar un lenguaje neutro, terminó describiendo a la gente que asistía al Cine Obrero como "burdos" y como personas que no sabían hablar con propiedad. Otras, como María Elena (1934), lo puso de manera más políticamente correcta:

María Elena (1934): Dejé de ir al cine más o menos cuando el Cine Elizondo fue derrumbado [se refiere a 1982]. Pero también me gustaba mucho el Florida. Estaba el Lírico, pero ese cine era para personas extremadamente... para las clases bajas... 
¿Y qué tipo de gente acostumbraba a asistir al Florida y al Elizondo?

María Elena: Tipo como nosotros, de clase media.

¿Era diferente la gente que asistía al Cine Elizondo y la que asistía al Maravillas?

AlejandRo (1927): Eran personas diferentes. [Las personas que asistían al Cine Elizondo] iban muy bien vestidas y de inmediato te dabas cuenta de que era gente con dinero... Pagaban más por la calidad de las películas y por comodidad del cine... les gustaban películas que mostraban buenas costumbres. Eran muy chic... exhibían muy buenas películas. El Cine Encanto siempre tenía llenos. Podías oler los perfumes [de las damas] por todas partes. La gente iba muy bien vestida, como en el Elizondo... En el Maravillas [en contraste] la gente iba vestida como le daba la gana.

Enrique (1924) explicó que normalmente iba a los mejores cines ubicados en el centro de la ciudad, evitando siempre los cines de barrio, como los de la colonia Independencia, sector de la ciudad "con mala reputación". A la pregunta sobre diferencias entre los grandes cines del centro y las salas de barrio, otro informante contestó:

Andrés (1944): ¡Por supuesto [que había diferencias]! Decían que al entrar al cine Alameda, los empleados te daban un gran palo para matar a las ratas. La gente que asistía era muy mal educada: escupían en los asientos y éstos estaban en muy mal estado. Notabas la falta de educación en su comportamiento agresivo. Por eso evitaba ir a esos cines.

Otro de los informantes, de clase baja, mencionó que acostumbró por un tiempo a ir al Cine Edén, localizado en la ya mencionada colonia Independencia, debido a que vivía en dicho barrio popular cuando niño. "Ahí aprendí a ser peleonero y problemático", comentó bromeando, y agregó que las pandillas locales en esa colonia tiraban piedras a quienes se atrevían a pasar por sus calles.

Leonel (1927) explicó que cuando niño trabajaba limpiando calzado (bolero) en las calles y que le daba todas sus ganancias a su papá, quien trabajó por cuarenta años como obrero en la fábrica de jabón La Reynera. De- 
bido a su bajo sueldo, el papá llevaba al cine solo a la mitad de sus nueve hijos un fin de semana y a la otra el siguiente, pues no tenía suficiente para todos.

Leonel (1927): Íbamos al cine siempre por la noche, después de las 8:00 p. m., cuando oscurecía. Tan pronto se hacía de noche empezaba la función, pues la película se exhibía al aire libre, no en un edificio con techo. Así eran las terrazas. De vez en cuando mi papá nos llevaba a los cines normales, pero solo en muy pocas ocasiones... como esas salas eran mucho más caras, solo íbamos cuando él recibía un buen sueldo. Nos decía: "Ahora es cuándo. Mañana los llevaré a una sala de cine". Y así es como llegábamos a ir. Pero era muy esporádicamente. En las terrazas, no había techos. Cuando llovía, teníamos que correr y perdernos la película.

Enrique (96 años, nacido en 1915), uno de los informantes de mayor edad en la muestra, explicó que cuando niño un herrero iletrado le pagaba los boletos del cine a él y a otros niños del barrio, para que lo acompañaran y le leyeran los títulos de las películas mudas.

Con diversos cambios políticos internos en la década de 1930 que establecieron apoyos gubernamentales para la cultura y el cine, así como el inicio de la Segunda Guerra Mundial en Europa, la producción de películas mexicanas tuvo un auge significativo, el cual se reflejó en los patrones de exhibición de las salas regiomontanas. Mientras que en los 52 sábados de 1932 solo se contabilizaron 10 funciones para cintas mexicanas, el número de funciones dedicadas a producciones nacionales subió a 161 en 1942 y a 895 en 1952 (Lozano et al., 2012). Las películas de Hollywood, sin embargo, no desaparecieron de los cines regiomontanos. Por el contrario, a pesar del incremento en los títulos nacionales, la oferta de filmes en la ciudad siguió dominada por las cintas estadounidenses. Para 1962, las funciones de películas mexicanas habían descendido a 578 (29.8\%), ya que las cintas habían perdido su atractivo para las clases medias y habían quedado solo en el gusto de los niveles socioeconómicos bajos. Paralelamente, las películas de Hollywood habían decrecido durante este mismo periodo a $43 \%$ (su porcentaje más bajo desde 1922). Las producciones europeas (incluso filmes del Reino Unido y de España), en contraste, habían tenido un resurgimiento, ocupando hasta $21 \%$ del total de funciones en la ciudad durante la década de 1950 (Lozano et al., 2012). En suma, de la década de 1930 
a la de 1950, los regiomontanos experimentaron el predominio de las películas de Hollywood, la Época de Oro del Cine Mexicano y, finalmente, la crisis en la asistencia a las salas de cine debido al decremento en la calidad de los filmes nacionales y el surgimiento de otras alternativas de entretenimiento, como la televisión.

Los datos disponibles sobre la exhibición y programación de películas en Monterrey (Lozano et al., 2012) se corresponden con los títulos y el origen de las películas mencionadas por los informantes. En sus entrevistas, 15 de los títulos mencionados en diferentes momentos se referían a producciones nacionales, mientras que 43 se trataba de cintas estadounidenses. Coincidente con el boom del cine mexicano, la mayoría de las películas nacionales recordadas por los entrevistados pertenecía a la década de 1940, periodo en el que la Segunda Guerra Mundial propició una disminución en el flujo de cintas de Hollywood al país y en el que los apoyos gubernamentales para la financiación y distribución de cine en México fueron más altos (Fein, 1996; Serna, 2006). Para la década de 1950, sin embargo, los títulos más mencionados por los respondientes eran estadoundienses (14), mientras que las referencias a cintas mexicanas resultaban muy escasas.

Al igual que la actitud ambivalente de los informantes flamencos hacia las películas estadounidenses, ensalzando los filmes europeos pero reportando disfrutar también de las películas de Hollywood (Biltereyst, Meers y Van de Vijver, 2011), los de Monterrey experimentaban una situación similar entre las producciones de Hollywood y las nacionales. Por un lado, vertían comentarios muy positivos sobre las cintas y los actores mexicanos de su infancia o juventud, pero por otro también admiraban los filmes de Hollywood y recordaban a sus estrellas con mucho afecto.

\section{Películas mexicanas}

Los informantes regiomontanos de clase media y baja favorecían claramente las producciones nacionales durante su infancia y juventud. En las entrevistas, mencionaban como sus favoritos títulos y actores mexicanos. Muchas de las informantes explicaban que en esas épocas disfrutaban en especial de los melodramas. Enrique (1922), no muy afecto a dicho géne- 
ro, recordó cuando su mamá y su hermana le rogaron llevarlas al cine a ver Cuando los hijos se van, película estrenada en 1941. Las llevó a uno de los grandes palacios de la avenida Madero y se sentó en medio de las dos hermanas. Comentó que durante toda la función, las dos mujeres se la pasaron conteniendo el llanto, mientras que él se sentía incómodo por la situación. Cuenta que de regreso a casa, ninguna de las dos pronunció palabra alguna. Tan pronto arribaron, la mamá se bajó apresuradamente del auto y corrió a su recámara. Después de estacionarse, Enrique fue a buscarla y la encontró llorando. Su madre le dijo: "Aquí puedo llorar todo lo que quiera sin molestar a nadie y sin que nadie me calle”. El informante concluyó el relato diciendo: "Las películas mexicanas eran un verdadero drama”.

Reaccionando de manera similar a la mamá de Enrique, Elena (1929) comentó sobre el impacto duradero que tuvo dicha película en ella. Después de ofrecer un recuento detallado de la trama, explicó que lo que le afectó más fue la forma en que el padre y la madre, al final de sus vidas, eran explotados por sus hijos, quienes los visitaban solo para pedirles dinero o quitarles sus posesiones a pesar de su desastrosa situación económica.

Eso me impactó para siempre. Si fuera a ver la película de nuevo, estoy segura de que lloraría otra vez... su impacto fue muy fuerte en mí... sentir la pena de los padres cuando se quedan solos, sin la ayuda de ninguno de sus hijos a pesar de que les habían dado a ellos todo lo que tenían.

Otra de las informantes femeninas, Nancy (1941), también hizo comentarios sobre la impresión que le causó otro melodrama de esa época: Nosotros los pobres, estelarizada por el ídolo Pedro Infante y estrenado en 1948. Como muestra de una conexión emocional con situaciones urbanas y problemas familiares similar a la de las otras respondientes, Nancy recordó que en la cinta un niño pequeño moría y otro perdía un ojo de manera violenta. "Hasta hoy, soy incapaz de volver a ver esa película", dijo.

Algunos informantes comentaron que no les gustaban las películas estadounidenses, porque no entendían inglés y no podían leer los subtítulos (en México el doblaje de las películas no era ni obligatorio ni normal en esa época). Como niños, era difícil seguir los subtítulos, por lo que algunos 
de los entrevistados reportaron que no veían producciones de Hollywood durante esa etapa de sus vidas:

Nelly (1941): Había películas americanas, pero no íbamos a verlas. No íbamos porque no las entendíamos, no podíamos leer los subtítulos... como adolescente sí las empecé a ver, a colores y así, pero no de pequeña.

Otros explicaron que las salas económicas y las terrazas solo exhibían cintas nacionales y que las películas estadoundiense se reservaban para los grandes cines del centro, cuyo costo de admisión les impedía asistir.

José (1943): Las terrazas estaban más orientadas a las familias; exhibían mayormente títulos mexicanos... solo películas viejas, nunca estrenos. Si querías ver los estrenos, tenías que ir a los grandes cines del centro.

No todos los informantes de clase trabajadora, sin embargo, gustaban más de las cintas mexicanas que de las estadounidenses. Los más grandes, quienes vivieron su infancia en años anteriores al auge del cine mexicano, declaraban que sus filmes favoritos en la niñez eran los estadounidenses. Eustolio (1924), de origen rural, mencionó que de niño le encantaban los westerns, pues los personajes "se subían a sus caballos y se iban a disparar con sus pistolas".

\section{Películas estadounidenses}

Los entrevistados de clase media y alta, aunque mostraban simpatía por las producciones nacionales de la época de oro, reportaban mayormente haber visto y disfrutado de filmes de Hollywood y admirado estrellas, como Clark Gable, Rock Hudson, Ingrid Bergman, Bette Davis, Doris Day, Greta Garbo, Audrey Hepburn, James Dean, y otros. Como en los informantes flamencos en la investigación de Biltereyst, Meers y Van de Vijver (2011), los respondientes regiomontanos rara vez recordaban películas específicas, pero eran particularmente lúcidos acerca de sus estrellas favoritas de Hollywood.

En otro ejemplo de cuán extendidas y populares estaban las producciones de Hollywood alrededor del mundo a pesar de diferencias culturales y geográficas en las audiencias que las veían, los entrevistados en Monte- 
rrey, al igual que los flamencos y las informantes británicas de Kuhn, mencionaron repetidamente grandes eventos cinematográficos como Lo que el viento se llevó (Gone with the wind), Ben-Hur y King Kong.

\begin{abstract}
NeLly (1941): King Kong. Para mí, King Kong me dio el susto más horrendo de mi vida [se ríe]. En su primera versión, claro. Al final de la película, me fui a la casa muy asustada y tuve pesadillas no sé cuántas noches después. Para mí fue algo así como: "¡Oh, Dios mío!". Y después vi las nuevas versiones y también me impactaron, pero cuando eres grande te das cuenta de la fantasía, de los trucos... pero la primera vez... qué cosa tan horrible, jay Dios! A mí King Kong me provocó el trauma más grande de mi infancia.
\end{abstract}

Para algunos informantes, Ben-Hur fue una de sus películas favoritas de todos los tiempos. Mariana (1944), por ejemplo, explicó que ese filme le encantó desde la primera vez, y no se cansa de verlo cada año, cuando es programado en televisión durante la Semana Santa.

\title{
Filmes europeos
}

Muy pocos informantes mencionaron películas europeas. El mercado cinematográfico en México estuvo dominado por Hollywood desde 1917 (y por Hollywood y las producciones nacionales a partir de 1937) y las cintas provenientes de países europeos no eran muy comunes, excepto a partir de fines de la década de 1950 y principios de la de 1960, cuando se vivió un auge relativo, que llegó a ocupar $13 \%$ del tiempo de pantalla (Lozano et al., 2012). El carácter más liberal de estas películas, muy contrastante con las de la rígida moral de la época en México, así como los desnudos y los temas controversiales en ellas, las limitó a cines para audiencias de bajo nivel socioeconómico y a ser percibidas como "pornografía”. Algunos entrevistados, en especial las mujeres, hicieron referencia a esta percepción al ser cuestionadas sobre las películas que les gustaba ver cuando ya eran adultos:

THELMA (1935): ¡Solo me gustaban las películas [norte]americanas! Las mexicanas empezaron a ponerse feas y dejamos de ir a verlas, y las europeas solo las veíamos dependiendo de dónde las programaban. Si las exhibían en cines que pasaban pornografía, entonces no íbamos a verlas. 
NeıLy (1941): Definitivamente, solo [norte]americanas. Las europeas... no sé por qué eran tan crudas, tan... de mente abierta... no me gustaba eso... desnudos y esas cosas iban contra mis principios.

Andrés (1944): Una vez fui al Cine Alameda, porque me dijeron que estaban pasando una "película de arte", una de esas cintas italianas muy sofisticadas para el público en general... Las veo ahora, y logro captar su intención, pero en aquel entonces tú ibas a verlas solo por las chicas desnudas que aparecían en ellas.

Sin salas especializadas en cine de arte o de autor, y con una infraestructura y tradición culturales muy poco sofisticadas en la ciudad, la mayoría de los informantes de Monterrey era incapaz de mencionar filmes, directores o actores no comerciales, en contraste con informantes en Guadalajara, ciudad con mucha mayor tradición cultural y artística en esa época (Torres de San Martín, 2006). Solo dos respondientes, los de mayor edad en la muestra, mencionaron algunas películas europeas clásicas de las décadas 1930 y 1940: El ángel azul y El ladrón de bicicletas:

EnRIQUe (1922): Había algunas películas italianas muy buenas, como la del hombre al que le roban la bicicleta, El ladrón de bicicletas se llamaba. Los filmes italianos como ese eran una garantía: muy interesantes y bien hechos.

Algunas películas españolas de fines de la década de 1950 e inicios de la de 1960 fueron mencionadas también por algunos de los informantes: las comedias musicales románticas estelarizadas por cantantes, como Rocío Durcal, Marisol y Raphael.

\section{Actores más mencionados}

Coincidente con los datos sobre el origen de las películas exhibidas en la ciudad (Lozano et al., 2012), los actores más mencionados por los informantes para las décadas de 1920 y 1930 eran mayormente estadounidenses (o extranjeros) que aparecían en las cintas de Hollywood, contra una combinación de actores mexicanos y estadounidenses para las décadas de 1940 a 1960. Es interesante observar cómo las películas mexicanas recordadas se relacionaban con unos cuantos actores muy populares. A pesar de que el número total de producciones nacionales era muy inferior al de cin- 
tas estadounidenses, los actores mexicanos ocupaban un mayor número de funciones en las pantallas regiomontanas.

Algunas de las entrevistadas incluso mencionaron haber estado enamoradas platónicamente de algunos de los actores mexicanos de la época.

Beatriz (1939): Nosotras [ella y su amiga que acostumbraba acompañarla al cine] jugábamos a que una de las dos era esposa de Pedro Infante y la otra de Jorge Negrete. Otra amiga era la esposa de David Silva. En nuestra imaginación, estos actores eran nuestros esposos.

Sin embargo, aclaraba Beatriz, ya de más grande, dejaría de interesarse en los actores mexicanos y empezaría a centrarse en los estadounidenses, como James Dean. Mostrando un póster de Dean sobre la cómoda de su recámara, Beatriz señaló: "Él era mi novio, solo que nunca lo supo y murió en un accidente. Era mi ídolo”.

Un entrevistado de sexo masculino, de 89 años, reportó con mucho énfasis que nunca se perdía películas de Ingrid Bergman cuando joven. Otras entrevistadas, por su parte, mencionaron su fuerte atracción por actores estadounidenses. Olga (1923), por ejemplo, dijo que había estado locamente enamorada de Clark Gable: "Una de mis amigas incluso me regaló una almohada con la cara impresa de él”, explicó sonriendo. Antonia (1931) también mencionó a dicho actor, pero prefería a Paul Henreid, de quien dijo haber tenido muchos pósteres en su cuarto. Otra informante se refirió a una prima de ella que de joven enviaba cartas como fan a los actores estadounidenses que le gustaban:

NelLy (1941): Tengo una prima a la que le encantaba enviar cartas a los actores de Hollywood y, por supuesto, no ellos sino sus representantes le respondían enviándole fotos autografiadas. Nosotros las veíamos completamente emocionadas.

\section{La asistencia al cine, más un asunto familiar y para la interacción social que por los filmes}

Pese a las significativas diferencias históricas, culturales y geográficas entre Monterrey y las ciudades de los Estados Unidos o Europa de la misma 
época, los hallazgos de nuestras entrevistas focalizadas muestran marcadas similitudes sobre la forma en que los regiomontanos experimentaban la asistencia al cine y sobre cómo recuerdan haberlo hecho. Los informantes de Monterrey de mayor edad parecían relacionarse con el tipo de memorias atesoradas, preferencias, rituales de consumo y razones para asistir al cine presentes en respondientes de estudios realizados en Europa y los Estados Unidos.

Como en las audiencias flamencas (Biltereyst, Meers y Van de Vijver, 2011) y británicas (Kuhn, 2002, 2011), las memorias de los entrevistados regiomontanos sobre su asistencia al cine cuando jóvenes trataban mucho más sobre aspectos sociales y rituales que sobre filmes. La mayoría de las veces no recordaban títulos de películas específicas y, con frecuencia, eran incapaces de recordar el nombre de los actores. Sin embargo, eran muy claros y reiterativos sobre lo que ir al cine representaba para ellos cuando eran niños o jóvenes. Algunos señalaban cómo les encantaba ir a algún gran cine en particular debido a su decoración y sus pequeñas luces en el techo, que generaban la impresión de estar viendo las estrellas. Otros mencionaban que iban a un cine específico, porque ahí se organizaban concursos y premios durante los intermedios. Un informante de sexo masculino, en este sentido, explicó que los miércoles, en algunos cines, había concursos de canto en los intermedios o se invitaba a todo el público a cantar canciones específcas, cuya letra se proyectaba en la pantalla para que todos pudieran seguirla.

Otros indicaban haber ido al cine en días específicos de la semana con sus padres o parientes, sin importar qué películas se estaban exhibiendo. Al preguntarle sobre qué le venía a la mente al pensar en su asistencia al cine cuando niña, Antonia, de 80 años, contestó: "Ir los cuatro juntos [sus padres, su hermana y ella]. Beatriz, de 72, contestó a la misma pregunta: "Mis mejores amigas, mi amiga Yolanda ....”.

En suma, los informantes regiomontanos parecían mantener más "memorias de la asistencia al cine" (una de las tres categorías formuladas por Kuhn, para clasificar las diferentes remembranzas sobre el cine) que "memorias de escenas o imágenes", o "memorias situadas o posicionadas" de 
escenas, o películas relacionadas con la propia vida del respondiente. Así, siguiendo a Kuhn, el acto social esencial de ir al cine era de mucha mayor importancia para los respondientes que la actividad cultural de ver películas (2011, p. 93).

Sobre quién seleccionaba la película que verían al ir al cine, la respuesta recurrente fue que la película no era importante, sino que veían cualquier filme que estuviera siendo exhibido en la sala que preferían, sin importar el género o el tema.

\footnotetext{
ENRIQUe (1922): Usualmente iba al cine con mi hermano, pero no escogíamos qué película ver. Los diferentes cines exhibían las mismas películas. Para nosotros no se trataba de escoger cuál ver. Íbamos al cine y veíamos cualquier título que se estuviera exhibiendo.
}

Algunos, sobre todo las mujeres, eran más selectivas y preferían ver principalmente comedias románticas, pero muy pocas mencionaron ir al cine solo cuando les interesaba ver un filme en particular debido a su tema, actor o director, excepto en películas de gran impacto, como Ben-Hur. Ir al cine era una de las escasas alternativas de entretenimiento en la ciudad para los informantes regiomontanos. Al preguntárseles sobre otras opciones, señalaron solo actividades deportivas, como el béisbol (muy popular en Monterrey en esos años) o fútbol soccer, o cuando niños, jugar simplemente en la calle. Los ricos, explicaron, podían ir al Casino Monterrey (lugar muy exclusivo, con restaurante, cafetería, cuartos de juego y salón de baile), pero ellos no tenían más tipos de recreación que ir al cine.

\section{Memorias de tramas y películas}

En la tipología de Kuhn (2011) sobre las formas de memoria del cine, los recuerdos de escenas o imágenes constituyen el Tipo A, el más cercano a la recolección del filme. Al igual que en los resultados de su investigación sobre la década de 1930, los recuerdos sobre la trama completa de las películas, entre los entrevistados de Monterrey, eran muy escasos. En cambio, frecuentemente recordaban escenas específicas que les habían impactado que habían sido relevantes para ellos. Una mujer de 88 años, por ejemplo, al referirse a una de sus cintas favoritas, solo pudo acordarse de una escena 
en la que Bette Davis, al no tener nada más que ponerse para un gran baile, tomaba una cortina de su casa y se hacía un vestido con ella, al parecer confundiendo la actriz con Maureen O'Hare, en Lo que el viento se llevó. Un informante de sexo masculino, de 96 años, no se acordó del nombre ni de la trama general de una película que le impactó, pero describió con mucha precisión una escena en la que el protagonista queda ciego cuando la pólvora de su rifle le explota en la cara al dispararlo. Luego, ya casado, mencionó ir seguido al cine con su esposa, pero fue incapaz de recordar un solo título.

\section{Conclusiones}

El presente artículo se planteó como objetivo analizar la experiencia social histórica de asistencia al cine en Monterrey (Nuevo León, México) durante las décadas de 1930 a 1960, según entrevistas focalizadas con 28 informantes mayores de 65 años. Mediante temas clave relacionados con su infancia y su juventud, se exploraron sus memorias e impresiones duraderas sobre su asistencia al cine, las películas y los actores de las películas estadounidenses y nacionales.

Las memorias de los informantes regiomontanos discutidas en este trabajo, como se ha advertido en la investigación empírica de la asistencia histórica al cine (Kuhn, 2002) ciertamente parecen haber sido selectivas y subjetivas, pero se observan consistentes en su contextualización mediante la referencia hacia patrones y rutinas de su vida cotidiana. Al igual que en otros estudios recientes (Rosas, 1998, 2000; Richards, 2003; Treveri-Gennari, O’Rawe y Hipkins, 2011), los cines, queda claro, no eran lugares aislados del entorno social, sino espacios claves para la interacción y el reforzamiento de lazos familiares, amistosos y románticos. Para los regiomontanos, ir al cine significaba no solo ver películas entretenidas, sino compartirlas con conocidos, experimentar un sentido de colectividad. Por supuesto, estas memorias no deben considerarse testimonios fidedignos de los hábitos de asistencia al cine y preferencias cinematográficas de nuestros informantes. Como señala Acuña (2009) siguiendo a Jelin, la construcción de la memoria no es lineal, sino que se da en medio de "contradicciones, tensiones, silencios, conflictos, huecos y disyunciones ... [fungiendo como] una reconstrucción actualizada del pasado que actúa como un conjunto de estra- 
tegias que nos ayudan a definirnos ante el mundo” (p.3). Giménez (2009) coincide con lo anterior, señalando que la memoria tiene un papel activo y no se limita a "registrar, a rememorar o a reproducir mecánicamente el pasado, sino que realiza un verdadero trabajo sobre el pasado, un trabajo de selección, de reconstrucción y, a veces, de transfiguración o de idealización” (p. 21). Las remembranzas de nuestros informantes sobre la importancia del cine en su infancia y juventud, así, no deben entenderse más que como recreaciones personales y subjetivas, desde el presente, de sus lecturas y percepciones de lo que para ellos sigue significando esa parte de sus vidas. Pero es precisamente este sesgo el que nos permite atisbar en lo más profundo de sus emociones y experiencias con el cine. El testimonio actual sobre esas lejanas épocas estaría reflejando lo que realmente quedó sedimentado y arraigado en ellos sobre los cines, las películas y los actores, y lo que estos representan todavía en la contextualización de sus biografías.

Además del papel de las películas y los actores en la experiencia cinematográfica, este proyecto destaca la importancia histórica de las salas de cine en la vida personal, familiar y colectiva en Monterrey dentro del contexto histórico de su transformación de pequeña población en la provincia mexicana del norte a una de las ciudades más grandes e industrializadas del país. Los cines, queda claro, no eran lugares aislados del entorno social, sino espacios claves para la interacción y el reforzamiento de lazos familiares, amistosos y románticos. Para los regiomontanos, ir al cine significaba no solo ver películas entretenidas, sino compartirlas con conocidos, experimentar un sentido de colectividad.

En resumen, para nuestra muestra de regiomontanos de la tercera edad, es claro que la asistencia al cine habría sido una parte extremadamente relevante en sus vidas, en especial cuando niños y jóvenes. Ir al cine era un pretexto para interactuar con parientes o amigos, para escapar del calor, para entretenerse en una ciudad con muy pocas oportunidades de esparcimiento. Las memorias de películas, como en los Estados Unidos, el Reino Unido, Flandes y otros países en los que se ha estudiado la asistencia histórica al cine, trataban más sobre escenas específicas, dramáticas o sobre sus estrellas favoritas que sobre las tramas completas o los directores. Excepto 
por las películas más famosas y populares, claramente recordadas, el resto de las películas vistas durante la infancia o la juventud constituían mayormente una sucesión de eventos indistintos que ofrecían entretenimiento, escapismo y pretextos para actividades sociales y culturales.

La combinación de factores que se presentó a finales de la década de 1930 y principios de la de 1940 y que propició el surgimiento y auge del cine mexicano en toda América Latina, se refleja claramente en los recuerdos atesorados por los informantes regiomontanos sobre los artistas nacionales y sobre algunas películas en particular. El disfrute de cintas nacionales en esa época muestra que, cuando se presenta una contraoferta nacional de películas y estrategias de distribución adecuadas, el fenómeno de "proximidad cultural" que propone Straubhaar (2003) para explicar las preferencias televisivas locales sobre las extranjeras puede reproducirse igualmente en el consumo cinematográfico. Hallazgos como los presentados aquí contribuyen a entender mejor no solo las similitudes y concordancias en la historia sobre la asistencia al cine en diferentes países, sino también las situaciones únicas y peculiares que cada contexto político, económico, social y cultural generó en estos procesos de consumo cinematográfico.

Como conclusión a todo lo anterior, podemos reiterar que, si bien las memorias de asistencia al cine de los informantes no deben considerarse testimonios fidedignos ni sobre las salas y películas ni sobre sus propios patrones y rituales de consumo cinematográfico en las épocas rememoradas, dichos recuerdos resultan válidos para incursionar en sus percepciones actuales sobre aquellas épocas, sobre lo que se mantiene vivo en sus afectos, sus valoraciones duraderas sobre lo que significaron las salas de cine, las películas y los actores favoritos en sus vidas cotidianas y en su interacción social con familiares y amigos. Esa dimensión subjetiva e históricamente distorsionada pudiese reflejar mucho mejor la relación establecida por estas audiencias con el cine y la relevancia que este último sigue manteniendo en su memoria. A final de cuentas, podría argumentarse, la experiencia social del cine en estos habitantes del Monterrey en las décadas de 1930 a 1960 queda evidenciada como una de las matrices culturales más importantes con las que construyeron y consolidaron su sentido de identidad. 


\section{Referencias}

Acuña, L. G. (2009). El cine documental como herramienta en la construcción de la memoria y el pasado reciente. Clío \& Asociados, 13, 1-8.

Allen, R. C. (1990). From film exhibition to the history of film reception: reflections on the audience in film history. Screen, 31 (4), 347-56.

Biltereyst, D. (2015). "I think catholics didn't go to the cinema": catholic film exhibition strategies and cinema-going experiences in Belgium, 1930s-1960s. En D. Biltereyst y D. Treveri Gennari (eds.), Moralizing cinema: film, catholicism, and power (pp. 255-271). Nueva York: Routledge, Taylor \& Francis.

Biltereyst, D., Frankenberg, L., Hinojosa, L., Meers, P. y Lozano, J. C. (2011). Historical cinema audiences in context: reflections and experiences from oral history research projects on screen culture in Monterrey, Mexico and Flanders, Belgium. Londres: Cost Action y Westminister University.

Biltereyst, D., Meers, P. y Van de Vijver, L. (2011). Social class, experiences and distinction in Postwar Ghent. En R. Maltby, D. Biltereyst y P. Meers (eds.), Explorations in New Cinema History (pp. 101-124). Malden, USA/Oxford, UK: Wiley-Blackwell.

Cerutti, M., Ortega, I. y Palacios, L. (2000). Empresarios y empresas en el norte de México. Monterrey, del Estado oligárquico a la globalización. European Review of Latin American and Caribbean Studies, 69, 3-27.

De los Reyes, A. (1983). Los orígenes del cine. México: Fondo de Cultura Económica.

Fein, S. (1996). Hollywood and United States-Mexico relations in the Golden Age of Mexican cinema (Tesis doctoral). 
Giménez, G. (2009). Cultura, identidad y memoria: materiales para una sociología de los procesos culturales en las franjas fronterizas. Frontera Norte, 21(41), 7-32.

Jancovich, M. (2011). Time, scheduling and cinema-going. Media International Australia, 139, 88-95.

Kuhn, A. (2002). An everyday magic. Cinema and cultural memory. Londres: I. B. Tauris.

Kuhn, A. (2004). Heterotopia, heterochronia: Place and time in cinema memory. Screen, 45(2), 106-114.

Kumar Acharya, A. (2011). Urbanization and spatial changes in demographic characteristics in Monterrey's metropolitan region. Caminhos de Geografia, 12(39), 271-282. Recuperado de http://www. ig.ufu.br/revista/caminhos.html

Lozano, J. C., Biltereyst, D., Frankenberg, L., Meers, P. e Hinojosa, L. (2012). Exhibición y programación cinematográfica en Monterrey, México, de 1922 a 1962: un estudio de caso desde la perspectiva de la Nueva Historia del Cine. Global Media Journal México, 9(18), 7394. Recuperado de https://journals.tdl.org/gmjei/index.php/ GMJ_EI/article/view/37

Maltby, R. (2011). New Cinema Histories. En R. Maltby, D. Biltereyst y P. Meers (eds.), Explorations in New Cinema History (pp. 3-40). Malden: Wiley-Blackwell.

Maltby, R., Biltereyst, D. y Meers, P. (eds.) (2011). Explorations in New Cinema History. Malden: Wiley-Blackwell.

Meers, P., Biltereyst, D. y Van de Vijver, L. (2010). Metropolitan vs. rural cinema going in Flanders, 1925-1975. Screen, 51(3), 272-280. 
Peredo, F. (2009). La diplomacia del celuloide entre México y Estados Unidos: medios masivos, paranoia y la construcción de imágenes nacionales. Revista Mexicana de Política Exterior, 85, 93-135.

Richards, H. (2003). Memory reclamation of cinema-going in Bridgend, South Wales, 1930-1960. Historical Journal of Film, Radio and Television, 23(4), 341-355.

Rosas Mantecón, A. (1998). El cine y sus públicos en México: un balance bibliográfico. Versión, 8, 227-247.

Rosas Mantecón, A. (2000). Auge, ocaso y renacimiento de la exhibición de cine en la ciudad de México (1930-2000). Alteridades, $10(20), 107-116$.

Saldaña, J. P. (1988). ¿Y qué hicimos? Monterrey en el siglo XX. Monterrey: Producciones Al Voleo/El Troquel.

Saragoza, A. M. (2008). La élite de Monterrey y el estado mexicano (18801940). Monterrey: Fondo Editorial Nuevo León.

Serna, L. I. (2006). "We are going Yankee": American movies, mexican nationalism, transnational cinema, 1917-1935 (Tesis doctoral).

Silva, J. P. (2011). La época de oro del cine mexicano: la colonización de un imaginario social. Culturales, 7(13), 7-30.

Stacey, J. (1994). Star gazing: Hollywood cinema and female spectatorship in 1940s and 1950s. Londres: Routledge.

Stokes M.y Maltby, R. (eds.) (1999). Hollywood abroad: Audiences and cultural exchange. Londres: BFI.

Straubhaar, J. (2003). Choosing national TV: Cultural capital, language, and cultural proximity in Brazil. En M. G. Elasmar (ed.), The im- 
pact of international television: A paradigm shift (pp. 77-111). Mahwah, NJ, EUA: Lawrence Earlbaum Associates.

Taylor, H. (1989). Scarlett's women: Gone with the wind and its female fans. Londres: Virago.

Torres de San Martín, P. (2006). La memoria del cine como extensión de la memoria cultural. Culturales, 2(4), 50-79.

Treveri-Gennari, D., O’Rawe, C. y Hipkins, D. (2011). In search of italian cinema audiences in the 1940s and 1950s: Gender, genre and national identity. Participations: Journal of Audience \& Reception Studies, 8(2), 539-553.

Vellinga, M. (1988). Desigualdad, poder y cambio social en Monterrey. México: Siglo XXI.

Vizcaya, I. (1971). Los orígenes de la industrialización en Monterrey (18671920). Monterrey: Librería Tecnológico. 